\title{
IMPACTOS DA PARTICIPAÇÃO DE MULHERES EM INICIATIVAS DE ECONOMIA SOLIDÁRIA NO CARIRI PARAIBANO
}

Impacts of women's participation in Solidarity Economy initiatives in the Cariri Paraibano

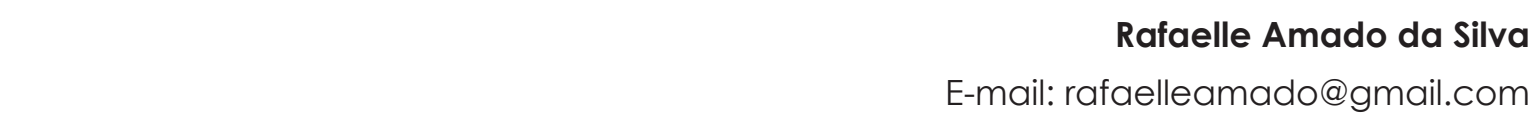

Graduada em Administração pela Universidade Federal de Campina Grande; Bolsista na

Energisa Borborema - Distribuidora de Energia. https://orcid.org/0000-0002-3422-2176

Verônica Macario de Oliveira

E-mail: veronicamacario@gmail.com

Doutora em Administração pela Universidade Federal de Pernambuco; Mestre em Engenharia de Produção pela Universidade Federal da Paraíba; Professora na Unidade Acadêmica de Administração e Contabilidade da Universidade Federal de Campina Grande. https://orcid.org/0000-0003-4194-9047

\section{Suzanne Érica Nóbrega Correia}

E-mail: suzanne.enc@gmail.com

Doutora em Administração pela Universidade Federal de Pernambuco; Mestre em Administração pela Universidade Federal da Paraíba; Professora Adjunta na Unidade Acadêmica de Administração e Contabilidade da Universidade Federal de Campina Grande. Endereço para contato: Universitário, 58429-900, Campina Grande, Paraíba, Brasil. https://orcid.org/0000-0003-3613-234X 


\section{Resumo}

Neste artigo objetivou-se identificar as possibilidades, desafios e transformações sociais no processo de emancipação feminina em empreendimentos solidários assistidos pelo projeto Mulheres Rurais: Autonomia e Empoderamento no Cariri Paraibano, na Cidade de Sumé, PB. Foi realizado um estudo de caso de natureza descritiva. Os resultados demonstram que a participação de mulheres em empreendimentos de Economia Solidária (ES) promove melhorias em suas vidas, integração com outras mulheres dentro de uma mesma realidade, melhores condições de trabalho e realização pessoal. Isso se relaciona a um processo de transformação social na medida em que auxilia no resgate de sua autoestima, impacta na busca por igualdade entre os gêneros e gera sua emancipação social. Porém, as integrantes das iniciativas investigadas enfrentam desafios relacionados à gestão do empreendimento, à infraestrutura inadequada, ao pouco retorno financeiro e à conciliação entre os afazeres domésticos e as atividades do grupo.

Palavras-chave: Economia Solidária. Emancipação feminina. Empreendimentos solidários. Inclusão social. Transformações sociais.

\section{Abstract}

This article aims to identify the impacts of Solidarity Economy (SE) in reference of possibilities, challenges and social transformations that stem from initiatives of in the process of female emancipation in solidarity projects assisted by the project Rural Women: Autonomy and Empowerment not Cariri Paraibano in the City of Sumé, PB. A descriptive case study was carried out. The results demonstrate that the participation of women in SE projects promotes: improvements in their lives, better working conditions and personal fulfillment. This is related to a process of social transformation insofar as it contributes to recover their self-esteem, impacts on the search for equality between genders and generates social emancipation. However, as members of SE initiatives, they face challenges that are related to enterprise management, inadequate infrastructure, little financial return, and reconciliation between household chores and group activities.

Keywords: Solidary Economy. Female emancipation. Social transformations. Enterprises solidary. Social inclusion.

\section{INTRODUÇÃO}

Em um contexto marcado por dificuldades e problemas sociais advindos, em sua maioria, de falhas no sistema capitalista, os empreendimentos de Economia Solidária (ES) surgem como uma alternativa para a inserção de pessoas no mercado de trabalho. Esses empreendimentos se baseiam no cooperativismo e possuem como objetivo a inclusão daquelas que estão excluídas, a partir da cooperação, solidariedade e processo participativo nas tomadas de decisão (Dias \& Souza, 2014).

As mulheres constituem um dos principais grupos que participam de iniciativas de economia solidária, em decorrência do longo período de exclusão do mercado de trabalho tradicional e da escassez de direitos sociais adquiridos. Essa representatividade feminina é justificada por sua necessidade de inserção em um ambiente que lhes proporcione um papel agregador de valor na sociedade e relações mais homogêneas quanto ao gênero. Diversos autores apontam os seguintes 
benefícios para as mulheres que estão inseridas em iniciativas de economia solidária: valorização do trabalho, geração de renda, independência financeira, conquistas de formulação e implantação de políticas públicas voltadas à questão de gênero e resgate de autoestima que se associam à possibilidade de emancipação feminina (Guerra \& Toledo, 2006; Mundim \& Teodósio, 2011; Messias \& Lima, 2014).

Em busca desses benefícios e como forma de combater os valores coronelistas, patriarcais e machistas que marcam o semiárido nordestino, a Cunhã Coletivo Feminista e o Centro da Mulher 08 de março iniciaram o projeto Mulheres Rurais: Autonomia e Empoderamento no Cariri Paraibano, focado em iniciativas de Economia Solidária (ES) a partir de ações educativas que visam contribuir para a organização política e produtiva das mulheres rurais, o empoderamento, a promoção de direitos e a redução das desigualdades de gênero presentes nesses locais. Compreender o impacto que iniciativas como essas trazem à vida das mulheres ainda é um desafio a ser investigado, para que se possa avançar nas discussões sobre o papel da ES no que tange às questões de gênero.

Desse modo, neste artigo teve-se como objetivo identificar as possibilidades, os desafios e as transformações sociais no processo de emancipação feminina nos empreendimentos assistidos pelo projeto Mulheres Rurais: Autonomia e Empoderamento no Cariri Paraibano, na Cidade de Sumé, PB. Para tanto, realizou-se um estudo de caso de natureza descritiva.

Em termos estruturais, este artigo se organiza em cinco seções. Além desta introdução, apresenta-se na segunda seção o referencial teórico que sustenta este estudo; na terceira seção estão os procedimentos metodológicos adotados; os resultados obtidos são apresentados e discutidos na quarta seção; e, por fim, tem-se as considerações finais.

\section{ECONOMIA SOLIDÁRIA: UMA BREVE EXPLANAÇÃO}

A Economia Solidária (ES) tem como base histórica o cooperativismo, visto como forma de reação ao desemprego e às condições de vida e de trabalho dos operários, e também como modo de produção alternativa ao capitalismo (Singer, 2008; Ramos, 2011 ; Silva \& Nagem, 2012).

Enquanto conceito, França (2001) ressalta que o termo economia solidária surge dos trabalhos de Jean Louis Laville e Bernard Eme, na França, que tentaram suprir " [. . .] a emergência e desenvolvimento do fenômeno de iniciativas e práticas socioeconômicas que visavam responder problemáticas locais específicas de exclusão social através das chamadas novas formas de solidariedade" (p. 2), propondo novos tipos de serviços chamados de "serviços solidários" ou "serviços de proximidade".

A partir desses serviços solidários, emergiram iniciativas locais baseadas em um novo caráter quanto ao seu funcionamento e à sua finalidade, denominadas Economia Solidária, no qual as atividades econômicas estão voltadas para fins sociais, tanto na geração de emprego quanto nos materiais, mas também no acesso igualitário à justiça e ao comércio, servindo também como um ambiente no qual os indivíduos participantes podem se abrigar das repressões políticas e sociais, da 
violência física e psíquica e de outras fontes de sofrimento (França, 2001; Silva, 201 1; Santos \& Oliveira, 2015).

França (2001) afirma que existem dois traços característicos que melhor expressam a especificidade das organizações de economia solidária:

a) a hibridação das economias não mercantis (há subsídios e financiamentos públicos), mercantis (existe venda de produto ou prestação de serviço a particulares) e não monetárias (contam com trabalho voluntário) que geram recursos os quais permitem a perenidade dos projetos criados pela organização e fazem com que a Economia Solidária seja interpretada como uma economia plural cuja experiência está situada nas esferas econômica, social e política;

b) a construção conjunta da oferta e da demanda, em que os serviços são propostos e concebidos em razão das necessidades sociais locais.

No Brasil, a economia solidária surgiu no início do século XX, a partir de cooperativas formadas inicialmente por emigrantes europeus, ressurgindo fortemente a partir de movimentos sociais em meados das décadas de 1980 e 1990, em reação ao desemprego em massa e à exclusão social provocados pela desindustrialização da época e pela abertura do mercado interno às importações (Singer, 2002).

Segundo a Secretaria Nacional de Economia Solidária e o Ministério do Trabalho e Emprego (Senaes/MTE, 2006), os empreendimentos de economia solidária buscam uma economia voltada para o desenvolvimento da população participante, a partir dos valores da solidariedade, da democracia, da cooperação, da preservação ambiental e dos direitos humanos. Esses empreendimentos podem ser cooperativas, associações ou grupos não formalizados, caracterizados por formas de produção e riqueza diferenciadas das demais economias enquanto suas ações e práticas (Costa \& Carrion, 2011).

Os princípios e as orientações da ES são apresentados na Tabela 1:

Tabela 1

Princípios e orientações para organizações de economia solidária

\begin{tabular}{ll}
\hline \multicolumn{1}{c}{ Princípios } & \multicolumn{1}{c}{ Orientação } \\
\hline Cooperação & $\begin{array}{l}\text { Existência de interesses e objetivos comuns a fim de trazer resultados positivos para todos } \\
\text { Os envolvidos. }\end{array}$ \\
Tutogestão & $\begin{array}{l}\text { Todos os participantes, de forma democrática, têm voz ativa em quaisquer decisões da } \\
\text { organização. } \\
\text { Deve existir em todas as dimensões da organização. }\end{array}$ \\
Valorização da diversidade & $\begin{array}{l}\text { Não deve haver discriminação em relação à crença, ao gênero, à raça ou à orientação } \\
\text { sexual. }\end{array}$ \\
Emancipação & $\begin{array}{l}\text { A organização de economia solidária deve proporcionar algum tipo de emancipação } \\
\text { para os indivíduos participantes. } \\
\text { Deve-se haver a justa distribuição dos ganhos obtidos pela organização, eliminando qual- } \\
\text { Justiça social }\end{array}$ \\
Ação econôno de desigualdade material para seus membros. \\
A fim de servir de base para a agregação de esforços e recursos pessoais na criação de \\
uma organização de economia solidária.
\end{tabular}

Nota. Adaptada de "Economia Solidária: Outra Economia Acontece!," por Secretaria Nacional de Economia Solidária e Ministério do Trabalho e Emprego, 2006. 
Esses princípios são importantes para a implantação de empreendimentos de economia solidária, uma vez que servem como orientação para as suas ações e os ajudam a cumprir suas finalidades.

Os empreendimentos de economia solidária aparecem, em grande número, como iniciativas que promovem geração de empregos e fonte de renda. Para as mulheres, os empreendimentos de economia solidária desempenham um papel importante nas suas vidas, pois estes podem transformar a participação delas na sociedade, assim como a identidade a elas relacionada (Culti, 2004).

Segundo o Sistema de Informações em Economia Solidária (SIES, 2013), no Brasil, ao final de 2013, as mulheres já eram 43,57\% do total de participantes de iniciativas de economia solidária. Essas participantes, apesar de algumas dificuldades, podem desfrutar de possibilidades e transformações sociais por meio dos empreendimentos de economia solidária, como será discutido a seguir.

\subsection{AS POSSIBILIDADES, DESAFIOS E TRANSFORMAÇÕES SOCIAIS DAS MULHERES NA ECONOMIA SOLIDÁRIA}

Durante toda a história, a sociedade de pensamento patriarcal incumbiu as responsabilidades domésticas e familiares às mulheres e a responsabilidade de provisão financeira e econômica da família aos homens. Peixoto, Ramos, e Pessoa (2008) afirmam que a inserção das mulheres no mercado de trabalho "[. . .] ocorreu em condições desiguais de tratamento, de tempo, de mobilidade, de espaço e de remuneração em relação aos homens" (p. 1), o que resultou em empregos precários, salários mais baixos, menor cobertura dos serviços de seguridade social e dificuldades de acesso aos direitos trabalhistas, além de poucas possibilidades de promoção e carreira (Ramos, 2011). Isso gera um processo de transformação social para essas mulheres e que também está permeado por alguns desafios.

Desse modo, a Tabela 2 apresenta uma síntese das possibilidades, desafios e transformações sociais decorrentes de empreendimentos de economia solidária que foram identificados na revisão de literatura deste estudo.

Tabela 2

Possibilidades, desafios e transformações sociais decorrentes da economia solidária

\begin{tabular}{lll}
\hline \multicolumn{1}{c}{ Dimensões } & \multicolumn{1}{c}{ Variáveis } & \multicolumn{1}{c}{ Principais autores } \\
\hline \multirow{2}{*}{ Possibilidades } & Conquista de independência financeira & Culti (2004); Guérin (2005); Mundim e \\
& Integração e compartilhamento de experiências e valores. & $\begin{array}{l}\text { Teodósio (2011); Ramos (2011); Messias e } \\
\text { Lima (2014). }\end{array}$ \\
\hline & Dificuldade de gestão. & \\
& Dificuldade na comercialização dos produtos. & \\
& Pouco acesso a recursos financeiros, falta de política de \\
& Créditos específica aos empreendimentos e falta de subsídio & Culti (2004); Guérin (2005); Peixoto et al. \\
governamental. & (2008); Mundim e Teodósio (2011); Ramos \\
& Falta de conhecimentos tecnológicos. & (2011). \\
& Falta de rede de relacionamentos para a troca de experiên- & \\
& cias e conhecimentos. & \\
& Falta de rendimento justo pelos trabalhos desempenhados. & \\
\hline
\end{tabular}




\begin{tabular}{lll}
\hline & Emancipação social. & \\
& Autonomia. & \\
Transforma- & Resgate de autoestima. & Culti (2004); Guérin (2005); Peixoto et al. \\
ções & Maior reconhecimento e visibilidade dos trabalhos. & (2008); Mundim e Teodósio (2011); Ramos \\
& Geração de renda. & (2011); Messias e Lima (2014). \\
& Superação de diferenças de gênero e desigualdades intra- & \\
& familiares. & \\
\hline
\end{tabular}

No que se refere às possibilidades, constata-se que as mulheres envolvidas em iniciativas de ES conseguem dialogar, compartilhar experiências, decidir, elaborar e colocar em prática projetos adequados aos seus contextos. Isso porque tais iniciativas são baseadas nos princípios de solidariedade e cooperação entre seus membros e o processo de organização ocorre a partir de relações de confiança e de reciprocidade. Essas experiências, mesmo que não sejam capazes de resolver todas as dificuldades que as mulheres enfrentam, ajudam-nas a superar algumas delas, a saber: algumas questões que envolvem as diferenças entre gênero e rompimento da divisão sexual do trabalho; desigualdades nas obrigações familiares; reconhecimento e maior visibilidade pelas atividades desempenhadas; possibilidade de emancipação social; conquista de independência financeira e autonomia pessoal; e acesso a direitos até então inalcançáveis (Culti, 2004; Guérin, 2005; Barreto \& De Paula, 2009; Mundim \& Teodósio, 2011; Ramos, 2011; Messias \& Lima, 2014). Essas mulheres "[. . .] têm tido a oportunidade de redesenhar-se como agentes, de mostrar seu potencial propositivo na economia e de posicionar-se contra uma série de estigmas sobre o perfil da mulher que trabalha" (Peixoto et al., 2008, p. 10).

Entretanto, apesar de as mulheres terem a possibilidade de obter vários benefícios decorrentes de sua participação em empreendimentos de economia solidária, elas enfrentam alguns desafios nesse processo, entre os quais podem-se destacar: falta de recursos e infraestrutura; falta de leis específicas; e alto déficit de qualificação e capacitação de pessoas resulta em precariedade e instabilidade dos empreendimentos de economia solidária, além de limites técnicos para a gestão do empreendimento (Sá \& Soares, 2005; Mundim \& Teodósio, 2011; Ramos, 2011 ; Onuma, Capelle, \& Mafra, 2015; Soares, Silva, \& Rebouças, 2016). Além disso, a falta de redes de relações entre os empreendimentos de economia solidária também é vista como um desafio, uma vez que tais redes poderiam beneficiar a compra de insumos para os empreendimentos, assim como possibilitar 0 compartilhamento de saberes e experiências entre eles (Mundim \& Teodósio, 2011; Silva, 2016).

Essas informações mostram que a economia solidária é um processo de transformação social (França, 2001; Rocha \& Cunha, 2009), uma vez que apesar dos desafios enfrentados, o engajamento de mulheres em tais iniciativas pode transformar a sua identidade na sociedade como uma forma efetiva de emancipação feminina, além de promover o regaste da sua autoestima e gerar sua autonomia, surgindo, portanto, várias possibilidades de melhoria de condições e qualidade de vida.

Os empreendimentos de economia solidária, constituídos e destinados à geração de trabalho e renda àquelas pessoas excluídas do mercado de trabalho tradicional, emergem como uma oportunidade para auxiliar as mulheres no combate às precariedades que enfrentam no mercado 
de trabalho (Castilho, Mariani, \& Garcia, 2012). Esses empreendimentos apresentam-se para elas como um meio de aliviar o cotidiano, resgatar a autoestima, além de ser uma forma de sanar as suas necessidades (Guérin, 2005; Mundim \& Teodósio, 2011; Ramos, 2011; Cezar \& Fantinel, 2018).

A seguir apresentam-se os procedimentos metodológicos desta pesquisa.

\section{PROCEDIMENTOS METODOLÓGICOS}

Neste artigo teve-se como objetivo identificar os impactos decorrentes de iniciativas de ES no que tange às possibilidades, desafios e transformações sociais, no processo de emancipação feminina nos empreendimentos assistidos pelo projeto Mulheres Rurais: Autonomia e Empoderamento no Cariri Paraibano, na Cidade de Sumé, PB. Para tanto, a metodologia utilizada neste estudo baseia-se em uma abordagem de pesquisa qualitativa de natureza descritiva, a partir do estudo de caso realizado nos grupos Mulheres de Fé e Art's Pesca, que são formados exclusivamente por mulheres e atuam na produção e comercialização de artesanatos feitos de fuxico e escamas de peixe.

As técnicas de coleta de dados adotadas foram entrevistas semiestruturadas, análise documental e observação não participante (Flick, 2008). Realizou-se uma pesquisa censitária com todas as participantes ativas dos grupos investigados, totalizando 10 respondentes. Por conseguinte, de modo a complementar essas informações, foram utilizados como fontes secundárias de pesquisa materiais disponíveis nos sites das organizações que apoiam e executam o projeto, conferindo credibilidade às informações colhidas.

Para a realização do tratamento e análise dos dados foi feita uma análise de conteúdo seguindo as etapas adotadas por Bardin (2011), nas seguintes etapas: pré-análise; exploração do material; e tratamento dos resultados e interpretações. Para auxiliar nas análises, foi utilizado o Atlas. ti como software de análise de dados qualitativos (SADQ), que permite uma melhor organização dos elementos da pesquisa, colocando-os em um único projeto e estruturando seus resultados em redes semânticas conceituais, possibilitando o enriquecimento da apresentação dos resultados desta pesquisa. Os resultados foram abordados segundo dimensões, categorias e indicadores e são apresentados a seguir.

\section{RESULTADOS}

Em 2002, a Cunhã Coletivo Feminista e o Centro da Mulher 08 de março (CM8M), em parceria com o Projeto Dom Helder Câmara, deram início ao projeto Mulheres Rurais: Autonomia e Empoderamento no Cariri Paraibano, atuando junto às mulheres participantes de empreendimentos solidários a fim de contribuir na sua organização política e produtiva, empoderamento e autonomia social e financeira, promoção de seus direitos, enfrentamento à pobreza e redução das desigualdades de gênero. O projeto atua em sete cidades do Cariri paraibano, sendo Sumé uma das cidades atendidas. 
Em Sumé, o projeto atua em dois grupos: Mulheres de Fé e Art's Pesca. Os grupos iniciaram suas atividades em 2009. As Mulheres de Fé produzem e comercializam artigos pessoais e para a casa com o uso de fuxico, e o grupo Art's Pesca trabalha com artesanato, bijuterias e artigos de decoração provenientes de escamas de peixe.

A seguir, são apresentados e discutidos os resultados encontrados a partir da pesquisa de campo. Os impactos avaliados foram divididos em três dimensões de análise: possibilidades, desafios e transformações sociais.

\subsection{POSSIBILIDADES PROVENIENTES DA ECONOMIA SOLIDÁRIA PARA AS MULHERES}

Quanto à dimensão possibilidades, decorrente de iniciativas de ES, foram identificadas três categorias de análise que se originaram dos empreendimentos solidários analisados, a saber: cooperação e compartilhamento de experiências, realização pessoal e condições de trabalho (Figura 1).

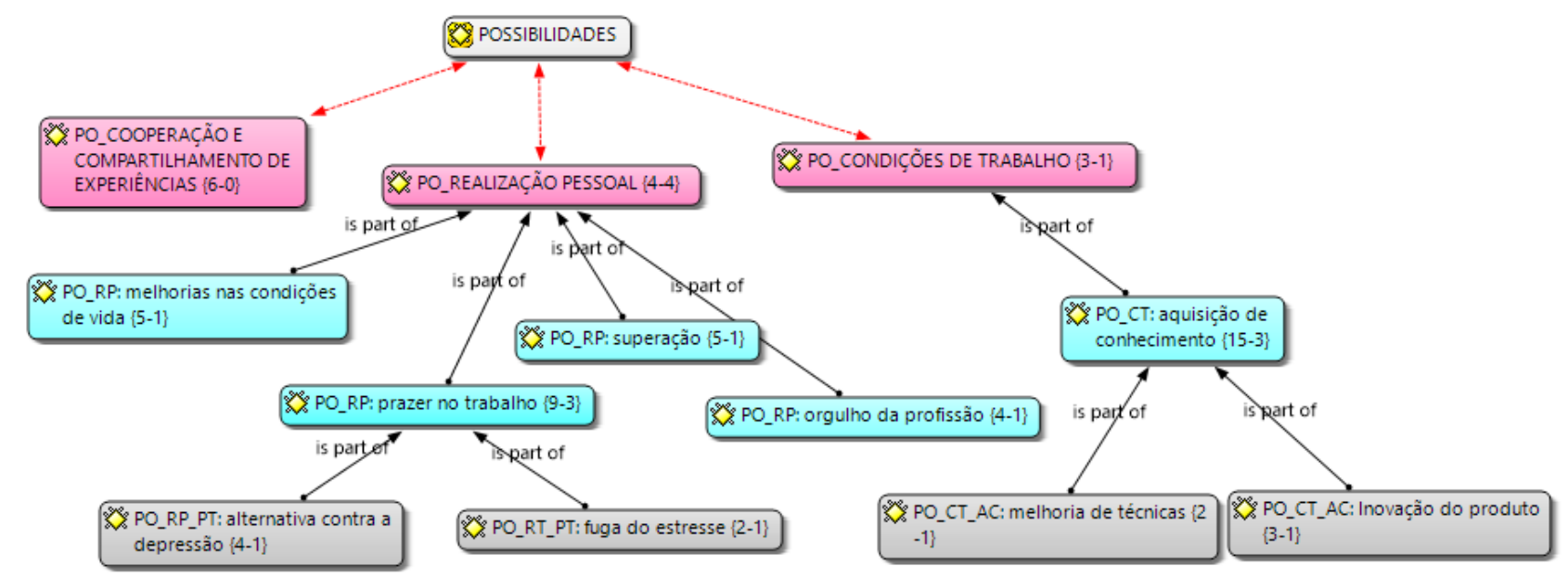

Figura 1. Possibilidades geradas em empreendimentos de economia solidária

Quanto à cooperação e compartilhamento de experiências, as entrevistadas afirmaram que a participação nos grupos lhes permitiu o convívio com outras mulheres de realidades semelhantes. As reuniões, viagens e oficinas que são oferecidas pelo projeto Mulheres Rurais: Autonomia e Empoderamento no Cariri Paraibano possibilitam uma alta troca de experiências que resulta em uma forte cooperação entre as participantes dos grupos, convergindo com a exposição de Singer (2002), que afirma que a colaboração e a igualdade são resultados naturais desse modelo de organização.

As realizações pessoais que as mulheres investigadas alcançaram a partir da participação nos grupos Mulheres de Fé e Art's Pesca também estão associadas às possibilidades provenientes de um empreendimento de Economia Solidária. Os indicadores dessa categoria de análise são:

a) a melhoria nas condições de vida; 
b) o prazer no trabalho, que é resultado do gosto de exercer a profissão de artesã e atua como alternativa contra a depressão e uma forma de fugir ao estresse do dia a dia;

c) a superação de desafios e obtenção de conquistas como a participação em feiras de artesanato e o acesso ao Programa Nacional de Alimentação Escolar (PNAE);

d) o orgulho de sua profissão, pois elas se sentem valorizadas e sentem que, por meio do grupo, elas têm um papel na sociedade, tanto na classe de pescadoras, para o grupo Art’s Pesca, quanto para o de artesãs em ambos os grupos. Os relatos a seguir confirmam esses indicadores:

\footnotetext{
... o Art's Pesca é meu mundo, eu sou apaixonada por esse grupo, mesmo assim sabe?̣! É minha vida [. . . .] é um trabalho como outro qualquer, só que esse trabalho me traz prazer . . . me me sinto bem, não é à toa que quando eu não faço o artesanato eu me estresso, pra mim isso é uma fuga do estresse .... . eu era estressada, eu era depressiva, eu vivia numa depressão profunda, era triste, chorava direto e a partir do grupo melhorou. (E03_AP)
}

eu faço coisas que achava que eu não era capaz e hoje eu sinto que eu sou capaz e posso fazer várias coisas. (E03_MF) (informações verbais)

A terceira categoria de análise identificada está relacionada com as condições de trabalho. Com a participação das mulheres nos empreendimentos solidários investigados, elas adquiriram novos conhecimentos e conseguiram refinar suas técnicas de desenvolvimentos dos produtos, resultando, assim, em melhorias na qualidade e especificações destes. Uma das entrevistas ressaltou "[. . .] aqui a gente consegue desenvolver melhor nossos trabalhos" (E03_MF), enquanto outra enfatizou "[. . .] a gente evoluiu, a gente inovou, acrescentou valor [. . .]" (E02_AP) (informações verbais).

Embora as mulheres tenham alcançado um bom leque de possibilidades decorrentes de sua participação nos empreendimentos investigados, elas também enfrentam alguns desafios, abordados na seção a seguir.

\subsection{DESAFIOS ENFRENTADOS PELAS MULHERES EM EMPREENDIMENTOS SOLIDÁRIOS}

Quanto à dimensão desafios, foram identificadas quatro categorias de análises, a saber: dificuldade de gestão, dupla jornada, pouco retorno financeiro, falta de recursos e infraestrutura (Figura 2). 


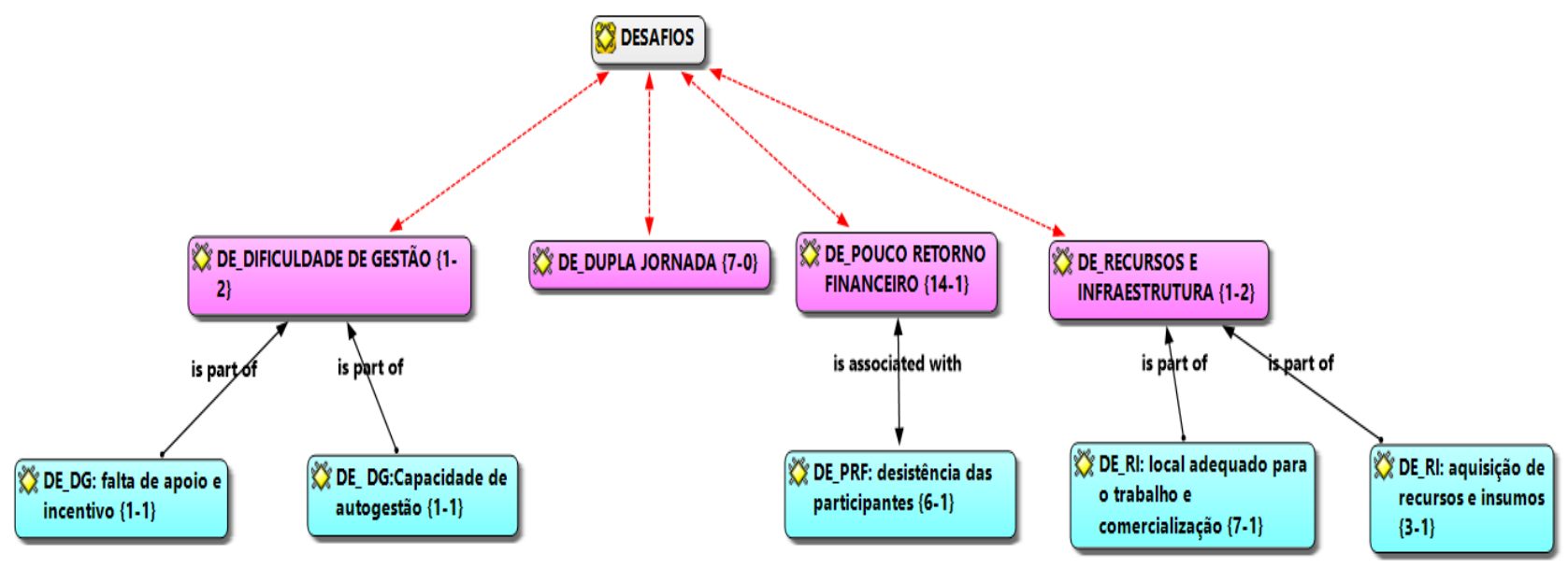

Figura 2. Desafios presentes em um empreendimento de economia solidária

A dificuldade de gestão se relaciona com os seguintes indicadores: falta de apoio e incentivo; e capacidade de autogestão. Embora os grupos tenham conseguido algumas parcerias mediante projetos de outras organizações, ainda é precário o apoio dos governantes da região onde os grupos estão localizados; além de não haver políticas específicas, o Estado não fornece subsídios ou incentivos para os grupos, o que dificulta a perenidade e evolução das iniciativas. Além disso, as mulheres investigadas sentem dificuldades na execução correta da autogestão. A tomada de decisão é geralmente centralizada em uma única pessoa, o que se contrapõe ao princípio de autogestão em que todos os sócios do empreendimento de ES devem estar informados de todas as alternativas disponíveis para a resolução de um problema (Singer, 2002; Faria, 2017).

A dupla jornada enfrentada pelas mulheres investigadas apresenta-se como mais um desafio para a sua participação em iniciativas de ES. Todas as entrevistadas responderam que embora tenham responsabilidades com os trabalhos dos grupos, continuam sendo as principais responsáveis pelos serviços domésticos, o que as faz se sentirem sobrecarregadas. Ressalta-se que a sobrecarga a que as mulheres se referem não é decorrente da produção que o grupo demanda, mas das tarefas domésticas cotidianas, conforme pode se observar na seguinte fala: "às vezes eu quero trabalhar, fazer minhas coisas de artesanato e tenho que fazer os outros afazeres de dona de casa" (E04_MF) (informação verbal).

Os desafios relacionados à categoria de análise que envolve recursos, insumos e infraestrutura refletem uma precariedade no local de trabalho e de comercialização dos produtos provenientes das iniciativas investigadas. Um indicador dessa categoria foi a falta de local adequado para a confecção e produção dos artesanatos, restando como solução a produção dos produtos nas casas das integrantes do grupo e a dificuldade em ter um local fixo para a comercialização dos produtos já acabados. As investigadas afirmaram que não ter um local no qual possam ter as suas peças expostas para o público, o que dificulta o conhecimento da população sobre a existência de seus produtos e, consequentemente, prejudica as suas vendas, como afirmaram as entrevistadas a seguir. 


\footnotetext{
Acho que a principal dificuldade é não ter um local fixo pra gente fazer nosso artesanato, porque essas peças são muito delicadas e exigem muito cuidado então se a gente ficar pulando de casa em casa perde muita coisa. (E05_AP)

... a gente nunca acha como vender as peças, sabe? Às vezes a gente faz e fica com elas em casa porque não encontra a quem vender. (E01_MF) (informações verbais)
}

Essas situações corroboram a afirmação de Teixeira (2003) de que a comercialização é uma das principais dificuldades nos empreendimentos de Economia Solidária, pois a lógica do mercado penaliza os mais fracos e com menor experiência. Além disso, a aquisição de material é outro indicador dos desafios dessa categoria de análise. As mulheres relataram que enfrentam dificuldades em comprar as matérias-primas necessárias para o desenvolvimento dos seus produtos, pois necessitam se deslocar para outra cidade e precisam arcar com os custos desse trajeto.

A última categoria de análise identificada da dimensão desafios foi o pouco retorno financeiro. O grupo Art's Pesca consegue obter uma renda mensal de no máximo $R \$ 200,00$ e as Mulheres de Fé de $R \$ 100,00$ por mulher integrante. Elas afirmaram que se tivessem melhores condições para desempenhar o trabalho e comercializar os produtos acabados conseguiriam ter um maior retorno financeiro, visto que têm consciência de suas habilidades e do que são capazes de fazer, e, por isso, almejam uma renda maior. O pouco retorno financeiro é o motivo principal da desistência de participantes dos grupos, o que causa o enfraquecimento dos empreendimentos, principalmente na luta por direitos coletivos e na capacidade de produção.

Apesar desses desafios, as investigadas enfatizaram que ocorreram transformações sociais nas suas vidas com a participação nas iniciativas de ES. Essas transformações sociais são apresentadas na seção a seguir.

\subsection{TRANSFORMAÇÕES SOCIAIS DECORRENTES DA PARTICIPAÇÃO EM EMPREENDIMENTOS DE ES}

A dimensão transformações sociais apresentou três categorias de análise: aumento da autoestima, emancipação e igualdade entre gêneros (Figura 3). 


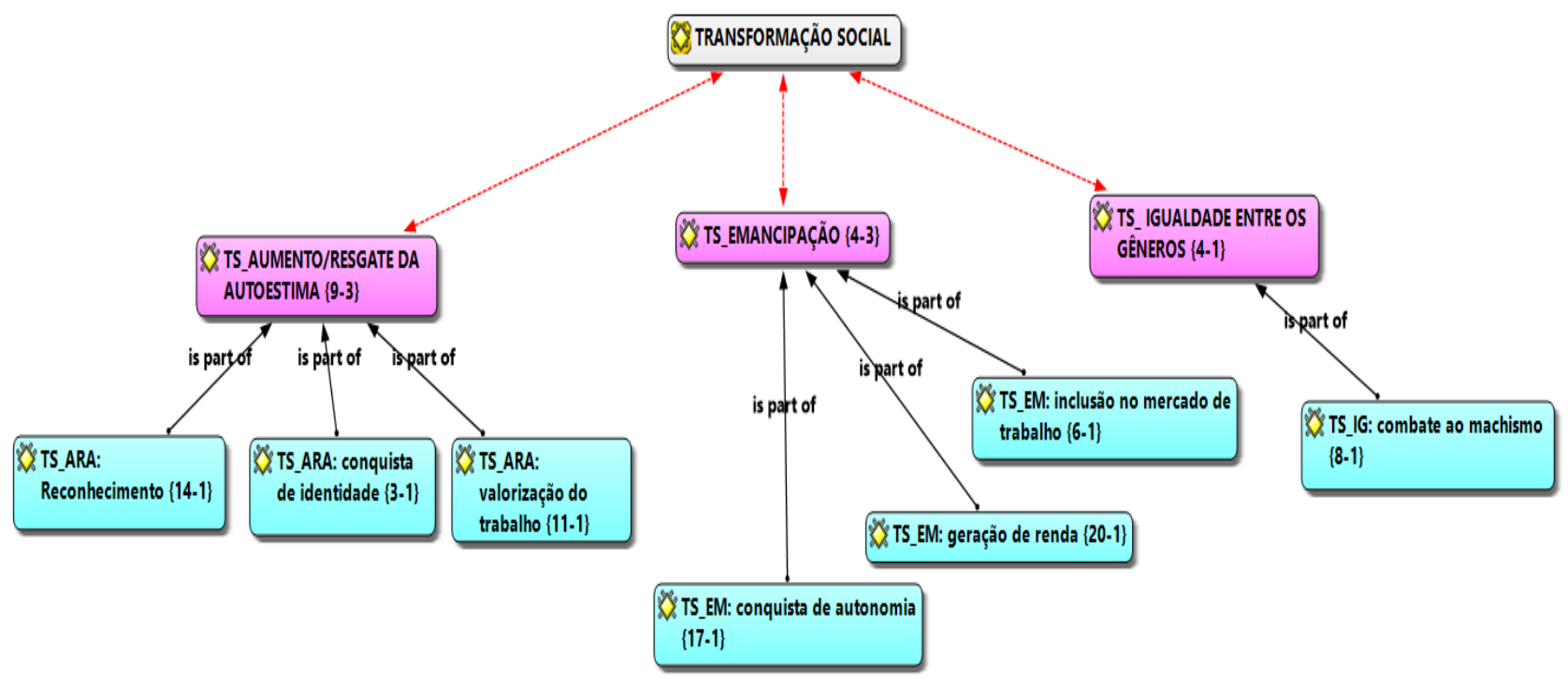

Figura 3. Transformações sociais na vida das mulheres participantes de empreendimentos de economia solidária

De acordo com as investigadas, o aumento ou resgate da autoestima foi um dos principais fatores de transformação social após sua participação nos empreendimentos. Os indicadores dessa categoria foram: sentimento de valorização por sua profissão e pelo que fazem; reconhecimento de seus trabalhos, não somente na cidade, mas principalmente em exposições que ocorrem em outras cidades; e construção de uma identidade que antes não possuíam. Atualmente as mulheres entrevistadas conseguem se ver como mulheres que exercem uma profissão e desempenham um papel importante nos grupos de ES que participam, como pode ser observado nas seguintes falas:

... é gratificante porque você é reconhecida e valorizada." (E04_MF)

... a principal conquista foi as mulheres se sentirem valorizadas e saber que elas conquistaram e trabalharam por uma boa causa, né?! E assim a melhoria foi na autoestima e elas se sentirem melhor como mulher, e a conquista também foi na categoria da pesca a gente ter um papel, néẹ! A gente se sente mais realizada dentro da profissão .... como mulher eu me senti realizada, me senti útil e ser respeitada o meu gosto, a minha opinião, a minha escolha, né?! (E02_AP) (informações verbais)

A pesquisa identificou também que as mulheres participantes dos empreendimentos de economia solidária estudados conseguiram sua emancipação, ou seja, alcançaram a independência em seus contextos sociais, financeiros e familiares, o que corrobora a afirmação de Guérin (2003), de que "[. . .] grupos constituídos por mulheres aparecem como suportes de emancipação individual" (p. 82). Os indicadores dessa categoria foram: inclusão no mercado de trabalho; geração de renda Ihes garantiu visibilidade, desvinculação das imagens das mulheres ao trabalho de seus maridos; e autonomia econômica para a aquisição de objetos pessoais e contribuição com a renda familiar e sociocultural.

Por fim, a categoria de análise que se refere à igualdade entre os gêneros teve como indicador o combate ao machismo, um aspecto cultural muito presente na região, o que corrobora a afirmativa de Lima e Soares (2011) de que "[. . .] a economia solidária pretende superar conceitos 
socialmente construídos de relações de gênero, demonstrando, na prática, uma maior igualdade entre homens e mulheres" (p. 8). As mulheres investigadas relataram que, a partir da participação nos grupos de ES e dos resultados alcançados, conseguiram desenvolver um trabalho que não depende da participação dos seus maridos, e, assim, foram capazes de mostrar aos homens da região que o trabalho que exercem é trabalho digno e que merece respeito.

\section{CONSIDERAÇÕES FINAIS}

A Economia Solidária (ES) se apresenta como uma nova forma de economia que possibilita aos seus participantes um ambiente voltado para o alcance do interesse coletivo. Alguns princípios que norteiam esses empreendimentos são: autogestão, solidariedade, cooperação e emancipação. No âmbito dessas discussões, neste artigo teve-se como objetivo identificar os impactos decorrentes de iniciativas de ES no que tange às possibilidades, desafios e transformações sociais, no processo de emancipação feminina em empreendimentos de economia solidária assistidos pelo projeto Mulheres Rurais: Autonomia e Empoderamento no Cariri Paraibano, na Cidade de Sumé, PB.

Os resultados encontrados neste estudo se ajustam à literatura sobre economia solidária. No entanto, os principais autores sobre o tema tratam os seus aspectos de forma geral, de modo que a literatura investigada foi confrontada com os resultados obtidos enquadrando os aspectos das dimensões de possibilidades, desafios e transformação social considerando a questão de gênero, para atender ao objetivo neste estudo.

Com base nas análises realizadas foi possivel associar cada dimensão investigada às suas categorias de análise e aos seus respectivos indicadores. Algumas variáveis levantadas no referencial teórico deste estudo foram reordenadas, ora como categoria, ora como indicador, e emergiram outras variáveis durante a realização do estudo. Quanto às possibilidades, surgiu uma nova categoria de análise associada às "condições de trabalho" e a "conquista de independência financeira" foi ampliada no seu significado e renomeada para a "realização pessoal". No que se refere aos desafios, a "dupla jornada" foi identificada como uma nova categoria de análise que está diretamente associada à questão de gênero, dado o acúmulo com as atividades domésticas desempenhadas pelas mulheres investigadas. Tais atividades são culturalmente reconhecidas como atribuições do gênero feminino. E, por fim, os resultados obtidos referentes a transformações sociais foram reestruturados em três categoriais de análise que envolvem aspectos relacionados ao aumento da autoestima, ao processo de emancipação e à diminuição das desigualdades entre gêneros.

Ressalta-se que os principais desafios apontados na pesquisa envolvem aspectos relacionados à disponibilidade de recursos e infraestrutura, o que remete à importância de desenvolver mecanismos de apoio para que tais iniciativas possam prosperar e ser difundidas em contextos com necessidades semelhantes. Isso pode ocorrer a partir da articulação e parcerias com atores governamentais que podem promover políticas públicas de fomento a esse tipo de empreendimento, bem como com atores da sociedade civil, a exemplo da ONG Cunhã Coletivo Feminista, que oferece suporte às iniciativas investigadas neste estudo, a partir do Projeto Mulheres Rurais: Autonomia e Empoderamento no Cariri Paraibano. 
Destarte, considera-se que esta pesquisa pode gerar respaldo para os novos estudos que relacionam gênero e economia solidária, possibilitando o aprofundamento nas dimensões, categorias de análise e indicadores apresentados. Acredita-se que esses estudos podem contribuir para o entendimento de como os empreendimentos de Economia Solidária geram impactos na emancipação feminina.

\section{REFERÊNCIAS}

Bardin, L. (2011). Análise de conteúdo. Lisboa: Edições 70.

Barreto, R. de O., \& De Paula, A. P. P. (2009). Os dilemas da economia solidária: um estudo acerca da dificuldade de inserção dos indivíduos na lógica cooperativista. Cadernos EBAPE, BR, 7(2).

Castilho, M. A., Mariani, M. A. P., \& Garcia, R. A. M. (2012). Economía solidaria y condiciones de autogestión en emprendimientos económicos solidarios en el municipio de Aquidauana (MS-Brasil). Estudios y perspectivas en turismo, 21 (5), 1225-1243.

Cezar, L. C., \& Fantinel, L. D. (2018). The sales of craft over a Lively Talk and a cup of Coffee: Social representations in a commercialization center of solidarity economy. BBR. Brazilian Business Review, 15(5), 475-493.

Costa, P. de A., \& Carrion, R. da S. M. (2011). Situando a Economia Solidária no Campo dos Estudos Organizacionais. Otra Economía, 3(4), 66-81.

Culti, M. N. (2004). Mulheres na Economia Solidária: Desafios sociais e políticos. Anais do Congresso Europeu CEISAL de Latino-americanistas, Bratislava, Eslovaquia, 4.

Dias, T. F., \& Souza, W. J. (2014). Gestão social e economia solidária: O caso da Associação dos Produtores e Produtoras Rurais da Feira Agroecológica de Mossoró-Aprofam, Mossoró-RN. TPA-Teoria e Prática em Administração, 4(1), 261-294.

Faria, J. H. (2017). Autogestão, economia solidária e organização coletivista de produção associada: Em direção ao rigor conceitual. Cadernos EBAPE. BR, 15(3), 629-650.

Flick, U. (2008). Introdução à pesquisa qualitativa-3. Porto Alegre: Artmed.

França, G. C., Filho. (2001). Novos arranjos organizacionais possíveis? O fenômeno da economia solidária em questão (precisões e complementos). Organizações \& Sociedade, 8(20).

Guérin, I. (2003). Sociologia Econômica e Relações de Gênero. In Emílio, M., Teixeira, M., Nobre, M., \& Godinho, T. (Org.), Trabalho e Cidadania Ativa para as Mulheres: Desafios para as Políticas Públicas. São Paulo: Coordenadoria Especial da Mulher da Prefeitura Municipal de São Paulo. 
Guérin, I. (2005). Mulheres e a economia solidária (As). São Paulo: Edições Loyola.

Guerra, A. C., \& Toledo, D. A. da C. (2006). Economia solidária e relações de gênero: Analisando uma nova relação de trabalho. Anais do Encontro Anual da Anpad, Rio de Janeiro, RJ, 30.

Lima, G., \& Soares, M. L. (201 1). Mulheres, história e saberes: Construindo economia solidária. Anais da Jornada Internacional de Políticas Públicas, São Luis, MA, 5.

Messias, A. R., \& Lima, J. R. O. (2014). A mulher na economia popular e solidária: Ponderações a partir de uma experiência de incubação. Anais do Congresso Internacional interdisciplinar em Sociais e Humanas (CONINTER), Salvador, BA, 3.

Mundim, F. de L. C., \& Teodósio, A. dos S. (2011). (Des)Caminhos e Encruzilhadas das Mulheres na outra Economia: Um Estudo de Caso no Assentamento Rural das Pastorinhas. Gestão e Sociedade, 5(11), 104-120.

Onuma, F., Capelle, M., \& Mafra, F. (2015). Aproximações entre a Autogestão na Economia Solidária e em Proudhon: Um Convite à Reflexão no Campo da Economia Solidária. Anais do Encontro da Associação dos Programas de Pós-Graduação em Administração - Ananpad, Belo Horizonte, MG, 39.

Peixoto, S. L. F., Ramos, J. P., \& Pessoa, C. (2008). Economia Solidária e Feminista: Reflexões em torno da automonia econômica das mulheres. Anais do Encontro Internacional Trabalho e Formação de Trabalhadores, Fortaleza, CE, 2.

Ramos, A. T. A. (2011). Mulheres na Economia Solidária: Uma alternativa de Inserção Social ao Mercado de Trabalho. Anais do Congresso Lus Afro-Brasileiro de Ciências Sociais - Diversidades e (Des) Igualdades, Salvador-BA, 11.

Rocha, A. N., Filho, \& Cunha, L. A. G. (2009). Economia Solidária: Alternativa de desenvolvimento, geração de trabalho, renda e resistência à exclusão social. Emancipação, 9(1), 95-105.

Sá, M. G. de, \& Soares, G. J. de V. (2005). Reflexões sobre poder e controle nas organizações da economia solidária (OES): Um olhar à luz dos bichos de Orwell. Cadernos EBAPE. BR, 3(2), 01-13.

Santos, J. C., \& Oliveira, B. A. M. (2015). Possibilidades para a Psicologia na economia solidária: Atuação numa ITCP. Psicologia \& Sociedade, 27(2), 18.

Secretaria Nacional de Economia, Ministério do Trabalho e Emprego. (2006). Economia Solidária: Outra Economia Acontece! Cartilha da Campanha Nacional de Mobilização Social. 
Silva, F. R. F. (2016). Gênero, agroecologia e economia solidária: Estudo de caso do grupo de mulheres do Acampamento Recanto da Natureza em Laranjeiras do Sul-PR. Desenvolvimento e Meio Ambiente, 39.

Silva, M. N. (2011). A economia solidária e as novas possibilidades do mundo do trabalho. Âmbito Jurídico, (86).

Silva, S. P., \& Nagem, F. A. (2012). Dimensions of structural developments in the solidarity based economy: An analysis of the states Bahia and Paraná. Revista Econômica do Nordeste, 43(2), 297-312.

Singer, P. (2002). Introdução a economia solidária. São Paulo: Fundação Perseu Abramo.

Singer, P. (2008). Economia solidária. Estudos avançados, 22 (62), 289-314.

Sistema de Informações em Economia Solidária. (2013). Atlas Digital da Economia Solidária. Retirado de http://sies.ecosol.org.br/atlas

Soares, M., Silva, R., \& Rebouças, S. P. (2016). Complexidade e Capital Social na Economia Solidária: Evidências Empíricas dos Empreendimentos Organizados em Redes no Brasil. Anais do Encontro da Associação dos Programas de Pós-Graduação em Administração - Enanpad, Costa do Savipe, BA, 40.

Teixeira, M. (2003). Sociologia Econômica e Relações de Gênero. In Emílio, M., Teixeira, M., Nobre, M., \& Godinho, T. (Org.), Trabalho e Cidadania Ativa para as Mulheres: Desafios para as Políticas Públicas. São Paulo: Coordenadoria Especial da Mulher da Prefeitura Municipal de São Paulo.

\section{Como citar este artigo:}

ABNT

SILVA, Rafaelle Amado; OLIVEIRA, Verônica Macario de; NÓBREGA, Suzanne Érica. Impactos da participação de mulheres em iniciativas de Economia Solidária no Cariri Paraibano. RACE, Revista de Administração, Contabilidade e Economia, Joaçaba: Ed. Unoesc, v. 17, n. 3, p. 851-866, set./dez. 2018. Disponível em: <http://editora.unoesc.edu.br/index.php/race>. Acesso em: dia/mês/ano.

APA

Silva, R. A., Oliveira, V. M. de, \& Nóbrega, S. É. (2018). Impactos da participação de mulheres em iniciativas de Economia Solidária no Cariri Paraibano. RACE, Revista de Administração, Contabilidade e Economia, 17(3), 851-866. Retirado de http://editora.unoesc.edu.br/index.php/race 